\title{
Towards the sustainability of road transport through the introduction of Autonomous Vehicle Technology
}

\author{
B. Hardy ${ }^{1} \quad$ BSc(Hons) MPhil \\ R.A.Fenner ${ }^{1} \quad$ BSc(Hons) PhD CEng MICE FCIWEM \\ ${ }^{1}$ Centre for Sustainable Development, Cambridge University Engineering Department, UK
}

\begin{abstract}
The paper investigates the potential for Level 2 autonomous vehicle (AV) technology to improve four prevailing sustainability issues specifically on highways: high congestion levels, increasing accident rates, high $\mathrm{CO}_{2}$ emissions and poor journey time reliability. Co-operative Adaptive Cruise Control (CACC) shows potential to achieve high volume co-operative driving on highways by controlling these parameters and forming vehicle platoons. Accident rates, $\mathrm{CO}_{2}$ emissions and journey times can be reduced as a result. The risks of platooning are discussed and a minimum safe platoon headway is established to mitigate the risk of vehicle platoon collisions. This headway is applied to a real highway case study demonstrating the potential to increase notional highway design capacity from 3,600 vehicles per hour (vph) to 9,213 vph, with significant sustainability improvements possible. Recommendations are made to complete a number of policy implementation and technology development tasks aimed to create the best chance of achieving the identified sustainability benefits within a 20 year timeframe.
\end{abstract}

Keywords: Transport Planning, Traffic engineering, Sustainability, Autonomous Vehicles, congestion, emissions, highways

\section{Introduction}

Autonomous Vehicle Technology is gaining momentum during a period of unprecedented and potentially unmanageable growth in the automotive industry. Road transport is one of the fastest growing global sectors in relation to greenhouse gas (GHG) emissions currently accounting for $17 \%$ of all global anthropogenic $\mathrm{CO}_{2}$ emissions (International Energy Agency, 2012). Growth has steadily increased from 1.2Gt CO 2 /year in 1960 to $6.2 \mathrm{GtCO}_{2}$ /year in 2012 (The Shift Project Data Portal, 2014) caused by a sustained growth of the global vehicle population from 126 million in 1960 to 1.1 billion in 2011 (Davis et al, 2011). The upward trend is set to continue and the total vehicle population is expected to increase to 1.34 billion by 2016 (Zahren, 2012), and 2 billion by 2050 (International Transport Forum, 2011). If road transport $\mathrm{CO}_{2}$ emissions continue on their current trajectory, levels may reach $10.8 \mathrm{GtCO}_{2}$ /year by 2050. 
If the road transport sector is to take a proportionate share of the targeted $80 \%$ reduction in anthropogenic global carbon emission by 2050 (Edenhofer et al, 2014) then it must reduce vehicle borne emissions to $2.1 \mathrm{GtCO}_{2} /$ year by 2050; a figure that is one third of 2012 levels, yet must be achieved with a significantly higher vehicle population (2 billion, $81 \%$ higher than 2011). The road transport sector is unlikely to decarbonise before 2050 due to the lack of technologically mature alternatives to petroleum (International Transport Forum, 2011), meaning the challenge will probably be in supporting higher numbers of road movements while consuming significantly less fuel.

As a result of the growing vehicle population, road movements are forecasted to increase by $30 \%$ in 2030 and 50\% in 2050 (Miles et al, 2013). Higher traffic volumes could create additional stress on existing road networks leading to increased congestion and delays for highway users. Increasing vehicle movements and congestion have caused a growth in global accident rates, currently estimated by the World Health Organisation to be between 30 and 50 million injury-causing accidents per year (World Health Organisation, 2013).

A traditional government response to traffic congestion and high accident rates is to build more roads, thereby theoretically increasing notional design capacity and reducing congestion and accidents. It has long been established that building your way out of congestion is not always possible due to a phenomenon called 'induced traffic demand'; i.e. the attraction of more people to motorised transport as the availability of useable roads increases leading to traffic problems persisting in the long term (Douglass, B. L. Jr, 2002). Upgrade schemes also bear a significant economic, environmental and societal cost and are becoming increasingly unpopular as a way of improving road traffic conditions. The A14 highway has a disproportionately high rate of accidents and delays caused by excessive traffic volumes during peak hours, however the UK Government abandoned an upgrade scheme costing f1.2billion pounds for this road due to the cost being deemed unaffordable during the 2010 Comprehensive Spending Review (Department for Transport, 2011).

The automotive industry is confident that fully Autonomous Vehicles will be available to purchase and drive on the road by 2025 (Juliussen \& Carlson, 2014). When the technology does come to fruition, drivers will be able to enter an Autonomous Vehicle, type in a destination and let the car drive itself without any further human input. The reality is that automotive manufacturers, as well as Google and other major technology suppliers are progressing a concerted schedule of real world tests and technology development programmes aimed at proving Autonomous Vehicle technology as a reliable and marketable concept. Transport authorities in highly motorised countries are beginning to shape 
transport policy to reflect the rapid development of Autonomous Vehicle technology and four specific technology levels have been established as shown in Figure 1:

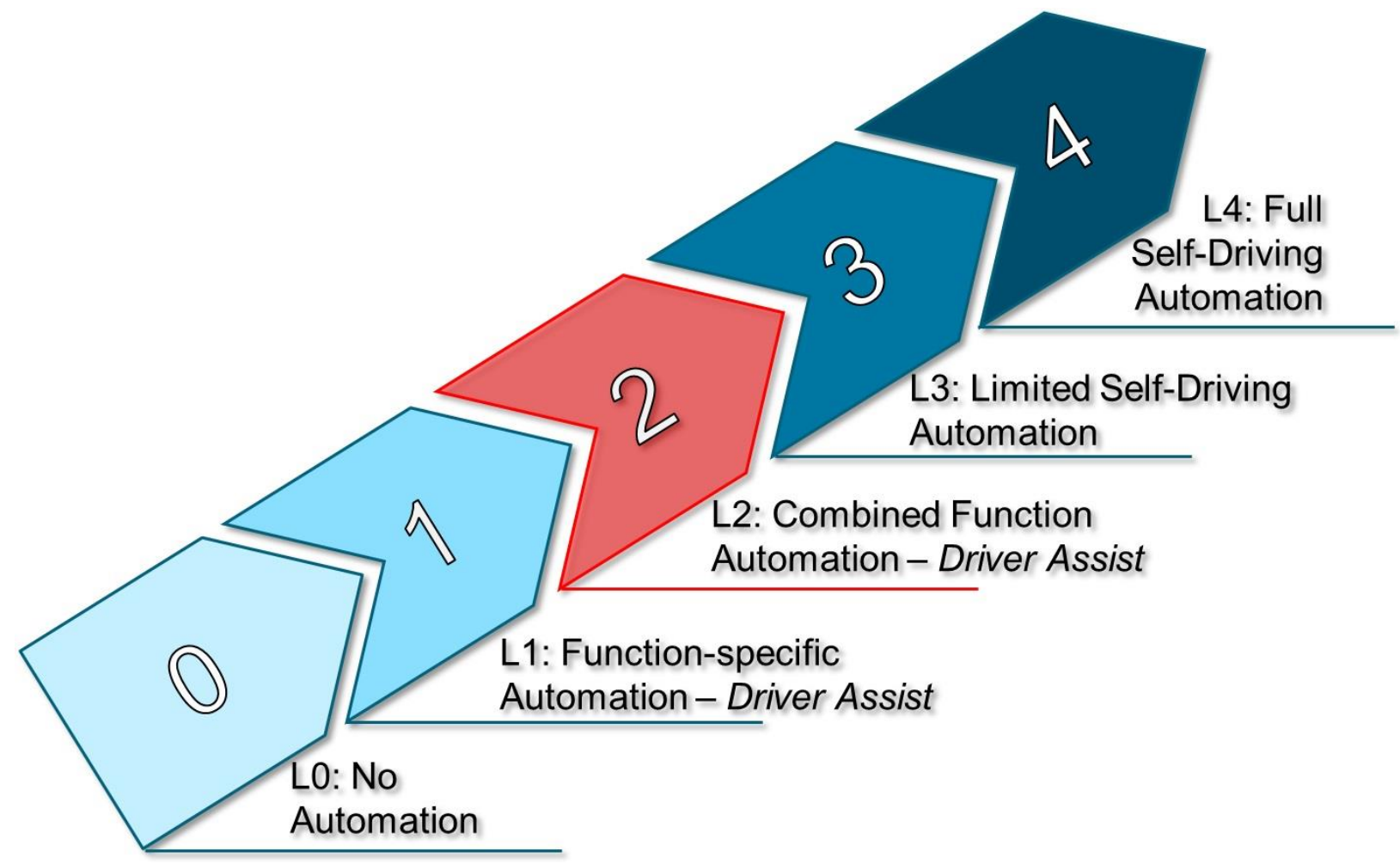

Figure 1: Different Levels of Autonomous Vehicle Technology (Developed from: NHTSA, 2013)

There is still much work to do before Level 4 Autonomous Vehicles are sufficiently capable of coping with the myriad of chaotic and random circumstances that are created on highways. Level 4 Autonomous Vehicles are underpinned by a vast array of sensors, processing hardware, operating systems and communication systems collectively enabling the vehicle to interpret its surroundings and navigate roads safely. The cost of this technology is currently very high. Level 4 Autonomous Vehicles rely on an infrared sensor made by Velodyne called the HDL-64 that creates a $360^{\circ}$ field of view, allowing Autonomous Vehicles to achieve a high level of situational awareness. The HDL-64 is recognised as a key component in achieving Level 4 autonomy and due to its complex design, each unit costs $£ 46,875$ (Petrie, 2013,). Even if Level 4 Autonomous Vehicles are developed and taken to market by the industry target date of 2025 , technology costs are expected to remain high resulting in forecasts that they will make up only 3.7\% of total global car sales in 2035 (Juliussen \& Carlson, 2014,). Many other issues such as insurance liability, policy implications, consumer trust in the technology and legal implications mean that the potential for Level 4 Autonomous Vehicles to replace manually driven cars is still unknown. Such uncertainty makes it difficult to make a reasonable assessment of the potential sustainability benefits that Level 4 Autonomous Vehicles may provide until the technology reaches a higher level of maturity and many of the issues hindering its development are addressed. 
Whereas Level 4 will be designed to take full vehicle control from a human driver, Level 2 Autonomous Vehicles systems can be used for the design of on-board features that aid humans in controlling vehicles efficiently and safely rather than taking full control from them. Level 2 systems such as Cooperative Adaptive Cruise Control (CACC) and Collision Mitigation Braking (CMB) are currently being tested by researchers and producing encouraging results. CACC utilises a vehicle-to-vehicle (V2V) communication protocol enabling vehicles to form platoons that share real time speed data so that uniform headways and similar constant velocities are achieved to potentially improve traffic flow. Highway capacities can be increased where smaller headways are maintained making more efficient use of road space and potentially reducing congestion as a result. Smaller platoon headways at highway speeds increase the risk of rear-end collisions necessitating the use of CMB to apply braking quickly where collision hazards are detected, potentially reducing accident rates. Because Level 2 Autonomous Vehicle technology has developed to a higher level of maturity than Level 4 systems with cheaper and simpler system architecture, it potentially offers a shorter route to market deployment. For the reasons discussed, this paper only assesses Level 2 AV systems with the objective of identifying how they could address a number of sustainability issues, including vehicle emissions, accident rates, congestion and journey time reliability.

\section{Potential Technology Applications}

\section{Co-operative Adaptive Cruise Control (CACC)}

CACC is an autonomous driver assist system combining an on-board radar sensor with a Vehicle to Vehicle (V2V) communication adapter known as 802.11p (Ploeg et al, 2011), enabling the formation of vehicle platoons ( Figure 2). A platoon leader is assigned, connecting to a string of following vehicles using V2V telematics to distribute real time information about its driving patterns. Vehicles that join the platoon use an on-board radar sensor to establish a pre-determined platoon headway while connecting with the platoon leader using $\mathrm{V} 2 \mathrm{~V}$ telematics. As the platoon leader accelerates or brakes it rapidly transmits velocity data back to following vehicles, theoretically allowing them to closely follow the same longitudinal driving pattern and facilitating the maintenance of uniform headways and similar constant velocities.

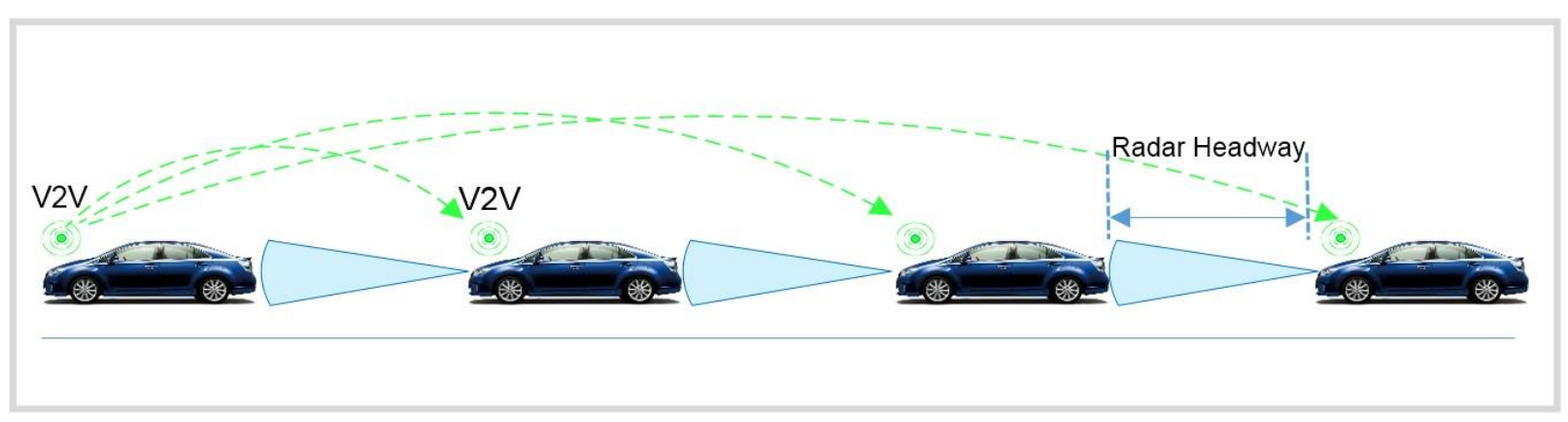

Figure 2: V2V telematics enable vehicle platooning using CACC. 
Tests using 6 Toyota Prius cars monitored the accuracy to which 5 platoon followers could duplicate the pattern of a platoon leader (Ploeg, 2012). Without deploying CACC, speed variations between platooned vehicles increased over time and cars further down the platoon were unable to follow the driving pattern of the lead vehicle (Figure 3a). At certain points cars at the rear of the platoon decelerated while the leader accelerated, demonstrating that the speed and headway stability within the platoon had broken down.

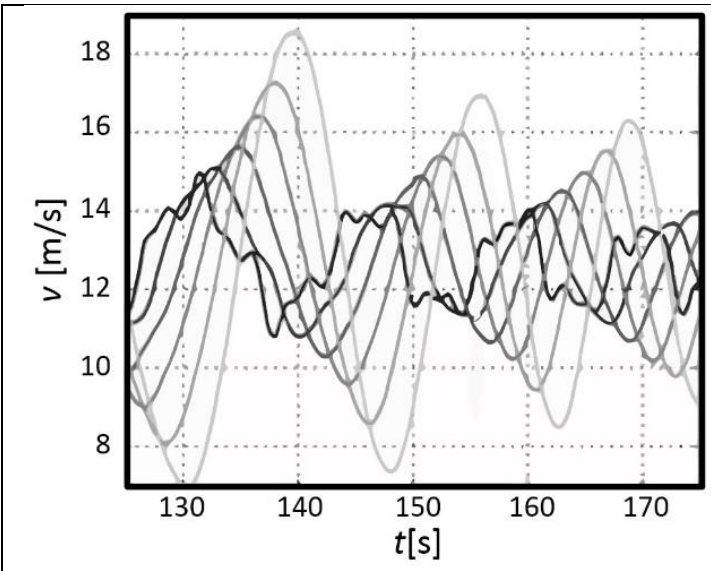

a) No CACC used

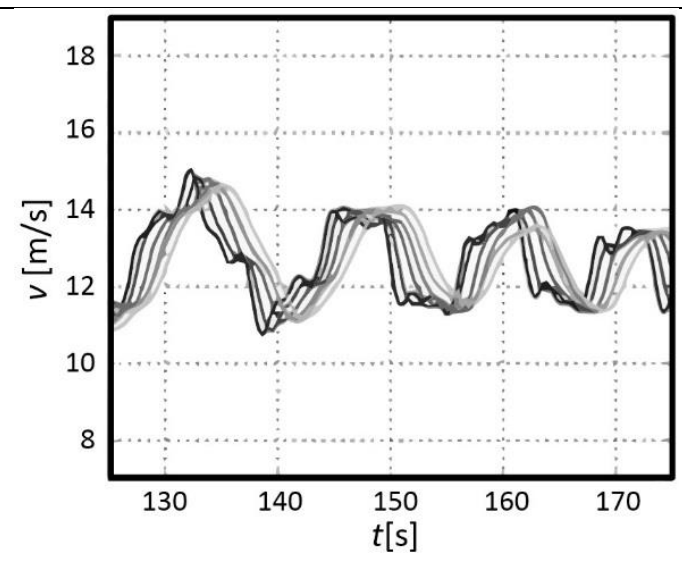

b) V2V telematics and CACC were utilised

Figure 3 : Car following pattern for platoon of 6 cars (adapted from (Ploeg, 2012))

Where all vehicles were equipped with CACC, a significantly different result was achieved. The platoon leader followed an identical driving pattern to the first run but also transmitted all speed changes to the following 5 vehicles within milliseconds using V2V communication. Figure $3 \mathrm{~b}$ ) demonstrates that all 6 vehicles were able to maintain a very similar driving pattern where uniform headway and similar velocities were more closely maintained than previous runs without CACC. The test also demonstrated that CACC virtually eliminated the effect of braking manoeuvres amplifying as they propagate upstream, highlighting the potential to reduce traffic jams where traffic density is high. The European Commission SARTRE (Safe Road Trains for the Environment) Project is examining a more ambitious 15 vehicle platoon with a uniform headway of $10 \mathrm{~m}$ at highway speeds (Smith, 2012).

The relevance of achieving small uniform platoon headways becomes clear when considered against highway policy governing safe vehicle spacing. The UK Highways Agency recommends that a spacing of 2 seconds is maintained between all highway vehicles travelling at 70mph (Department for Transport, 2006) allowing the average driver to interpret and react to potential hazards quickly enough to avoid or cause collisions. A headway of 2 seconds equates to $62 \mathrm{~m}$ at speeds of $70 \mathrm{mph}$, leading to Department for Transport (DfT) published notional design capacities of 3,600 vehicles per hour (vph) for dual 
carriageways and 5,400 vph for 3 lane motorways, based on Equation 1 where $n_{\text {veh }}$ is vehicles per hour per lane and $\mathrm{T}_{\min }$ is the minimums safe headway in seconds (distance/speed):

$n_{v e h}=\frac{3600}{T_{\min }}$

Equation 1

In reality hourly traffic throughputs regularly exceed these notional capacities, especially during peak hours, but DfT emphasises that they are associated with decreasing levels of service and safety for road users. Theoretically, if all traffic maintained a uniform headways of $10 \mathrm{~m}$ on highways at $70 \mathrm{mph}$, the notional design capacity would be increased to 22,536 vph over 2 lanes and 33,804 vph over 3 lanes. It seems unlikely that such figures could be achieved without dramatic advances in technology and complete optimisation of traffic co-ordination and flow. Practical testing of CACC has so far demonstrated that platooning has potential to facilitate platoon headways of less than $62 \mathrm{~m}$, but its ability to safely control headways of $10 \mathrm{~m}$ requires further testing.

\section{Collision Mitigation Braking (CMB)}

Vehicle platooning is being tested with the objective of minimising uniform platoon headways so the need for an additional safety system becomes apparent as reaction times to hazards reduce as headway reduces. Where brakes need to be applied CMB can be used in conjunction with CACC to ensure collisions are avoided where speed differences between platooned vehicles become higher. Because of the high speeds involved and objective to maintain small platoon headways, CMB seems to be an essential function in allowing CACC to operate safely.

Current CMB systems receive data from optical and radar sensors allowing a processor to interpret potential collisions (Delphi Corporation,2009) but there are limitations in application where small platoon headways apply. The processor can apply brakes to their maximum power using brake actuators to ensure collisions are avoided where hazards are detected. For the purpose of platooning with small headways such as $10 \mathrm{~m}$ it is doubtful that time would exist for the processor to interpret a dangerous speed difference and then apply braking with sufficient time to avoid a collision. A possible way to counteract this limitation is to use the $\mathrm{V} 2 \mathrm{~V}$ protocol as an additional trigger. In the case of a platoon leader braking heavily, the transmission of this information would then be received by platoon followers within $50 \mathrm{~ms}$ allowing more rapid activation.

\section{Risks}

The definition of a suitable headway distance for vehicle platooning on highways seems to be debated but currently undecided although a review of the application risks associated with CACC could lead to a more 
credible result. $\mathrm{V} 2 \mathrm{~V}$ communication systems are designed to ensure that safety critical information is transmitted to other vehicles with a maximum latency of $50 \mathrm{~ms}$ (Fernandes \& Nunes, 2012). Other road tests of $\mathrm{V} 2 \mathrm{~V}$ networked platoons have confirmed that signal strength is significantly weakened at ranges of over $70 \mathrm{~m}$ and where line of sight is disrupted between networked vehicles (Bergenhem et al, 2012). Testing of $\mathrm{V} 2 \mathrm{~V}$ signal latency has shown that data transmission delays can reach 0.3 s where an unstable signal exists (Zhou et al, 2012). Signal delays, particularly regarding the safety critical information used by $\mathrm{CMB}$, can lead to a higher collision risk where small headways are maintained.

Furthermore V2V signal is particularly vulnerable to interference from Unlicensed National Information Infrastructure (U-NII) devices operating at similar frequency bandwidths to the $5.9 \mathrm{GHz}$ frequency allocated to V2V adapters. Such a threat must be dealt with comprehensively as not only would unspecified signal dropout times cause unacceptable safety risks, they would also leave vehicle platoons vulnerable to external hacking and control. Interference could cause multiple vehicle collisions and create risk to human life.

Mechanical variations between vehicles also need to be considered which would affect the safe maintenance of small uniform headways. For example average braking distances between different cars vary depending on tyre grade, tread depth and weather conditions. Research has shown that tyres with a $3 \mathrm{~mm}$ tread have a $25 \%$ better performance than those at $1.6 \mathrm{~mm}$ in wet conditions. In terms of braking distance this represents an extra 8 metres (MIRA, 2014)

\section{Evaluating risk of collisions under small platoon headways}

Kinematic equations allow an accurate evaluation of the feasibility of $10 \mathrm{~m}$ uniform platoon headways at highway speeds considering the application risks identified above. As the risks are variable a number of potential scenarios will be evaluated to determine a minimum safe platoon headway based on the worst case scenario. The following kinematic equation will be used (Huang, 2002,):

$H_{s}=\frac{1}{2 a_{2}} v_{2}^{2}-\frac{1}{2 a_{1}} v_{1}^{2}+v_{2} T_{r}$ Equation 2

Where: $H_{s}=$ safe headway; $a=$ deceleration $\left(\mathrm{m} / \mathrm{s}^{2}\right) ; v=$ velocity $(\mathrm{m} / \mathrm{s}) ; T_{r}=$ Reaction time of platoon follower (Figure 4). 


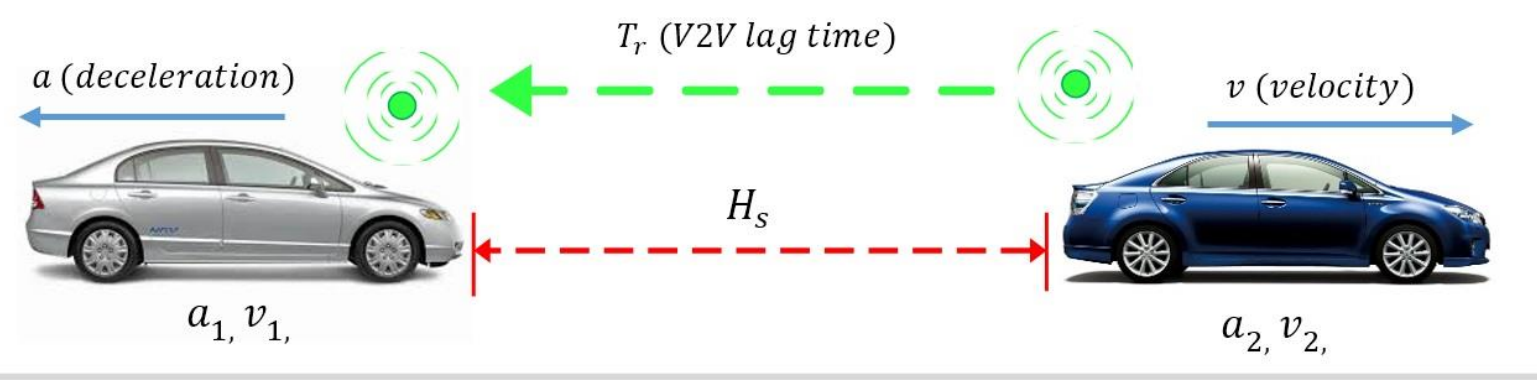

Figure 4: Contextualising Equation 2 parameters

The kinematic equations assume car deceleration profiles to be truly linear when in fact they are slightly curved. Accuracy of calculations should not be affected as all vehicles brake with a similar curve. The calculation below are based on modern cars decelerating at an average rate of $6.5 \mathrm{~m} / \mathrm{s}^{2}$ (Driver and Vehicles Standards Agency, 2007). '0.3' seconds is classified as high latency, so is used as the default V2V lag time. HGVs are not factored into the equations due to complex variations in braking performance.

There are four scenarios that will be considered to establish the worst case scenario resulting from a combination of application risks, and which allow for a relative difference in performance between vehicles. There are a large number of unknowable mechanical variations which can cause such performance differentials, so the calculations are based on assumed variations in tyre tread from $3 \mathrm{~mm}$ to $1.6 \mathrm{~mm}$ which directly affect braking distances :

Scenario 1. Vehicles have the same braking performance but $0.3 \mathrm{~s} \mathrm{~V} 2 \mathrm{~V}$ transmission lag exists.

Scenario 2. The platoon leader has a $25 \%$ braking performance advantage compared to the follower, and V2V lag exists.

Scenario 3. The platoon leader has a $25 \%$ braking performance advantage compared to the follower, but $\mathrm{V} 2 \mathrm{~V}$ is lag free.

Scenario 4. The platoon follower has a $25 \%$ braking performance advantage compared to the leader, and V2V lag exists.

\begin{tabular}{|l|l|l|}
\hline & Calculation & $\begin{array}{l}\text { Safe } \\
\text { Headway, Hs }\end{array}$ \\
\hline Scenario 1 & $H_{s}=\frac{1}{2 \times 6.5 \mathrm{~m} / \mathrm{s}^{2}} \times 31.3^{2}-\frac{1}{2 \times 6.5 \mathrm{~m} / \mathrm{s}^{2}} \times 31.3^{2}+31.3 \mathrm{~m} / \mathrm{s} \times 0.3 \mathrm{~s}$ & $\mathbf{9 . 3 9} \mathbf{~}$ \\
\hline Scenario 2 & $H_{s}=\frac{1}{2 \times 6.5 \mathrm{~m} / \mathrm{s}^{2}} \times 31.3^{2}-\frac{1}{2 \times 8.125 \mathrm{~m} / \mathrm{s}^{2}} \times 31.3^{2}+31.3 \mathrm{~m} / \mathrm{s} \times 0.3 \mathrm{~s}$ & $\mathbf{2 4 . 4 6 \mathbf { m }}$ \\
\hline Scenario 3 & $H_{s}=\frac{1}{2 \times 6.5 \mathrm{~m} / \mathrm{s}^{2}} \times 31.3^{2}-\frac{1}{2 \times 8.125 \mathrm{~m} / \mathrm{s}^{2}} \times 31.3^{2}+31.3 \mathrm{~m} / \mathrm{s} \times 0.05 \mathrm{~s}$ & $\mathbf{1 6 . 6 4 ~ \mathbf { ~ }}$ \\
\hline Scenario 4 & $H_{s}=31.3 \mathrm{~m} / \mathrm{s} \times 0.3 \mathrm{~s}$ & $\mathbf{9 . 3 9} \mathbf{m}$ \\
\hline
\end{tabular}

Table 1: Calculation of minimum safe platoon headway in four scenarios 
Safe headways under these scenarios are calculated in Table 1 . The results indicate that a platoon headway of $10 \mathrm{~m}$ is only suitable when the platoon follower has at least equal braking performance to the leader regardless of $\mathrm{V} 2 \mathrm{~V}$ transmission lag issues. Even in scenarios 1 and 4 where minimum safe headway is below $10 \mathrm{~m}$ the safety margin is minimal. In both scenarios where the platoon leader has a braking performance advantage, the maintenance of a $10 \mathrm{~m}$ platoon headway would result in a rear end collision if an emergency stop was conducted. If signal lag were to be eliminated then Scenario 3 demonstrates that platoon headway could be reduced to $16.64 \mathrm{~m}$, necessitating mitigation for braking performance variations only. Nevertheless platoon headways below $24.46 \mathrm{~m}$ would significantly increase the likelihood of rear end collisions and create an unnecessary safety risk.

Defining a minimum safe headway is important as it has a direct effect on the potential throughput of traffic on a stretch of highway. If inter-vehicle headway increases, vehicle throughput becomes more limited as vehicles become stretched out in space and time. Increasing platoon headways from $10 \mathrm{~m}$ to $24.46 \mathrm{~m}$ reduces maximum theoretical throughput across 2 lanes from 22,536 vph to 9,213 vph which still represents potential for more than a doubling of notional capacity

\section{Case Study: A14 between Huntingdon and Cambridge.}

The A14 dual carriageway running between Huntingdon and Cambridge is a 16 mile stretch of highway that suffers regular breakdown of traffic flow at peak hours due to excess traffic volumes. The notional design capacity is $3,600 \mathrm{vph}$ in each direction but actual flows often reach 7,200vph during peak hours (Department for Transport, 2011). Using a safe platoon headway (established above) of $24.46 \mathrm{~m}$ the effect on congestion, vehicle emissions, accident rates, and journey time reliability are discussed in the next sections.

\section{Congestion}

Even though the $\mathrm{A} 14$ speed limit is $70 \mathrm{mph}$, average traffic flow rate reduces to below $20 \mathrm{mph}$ during peak hours leading to traffic operating in 'stop and start' conditions (Department for Transport, 2011,). Congestion and delays for road users on this stretch of road are noted to be severe, suggesting that attention should be applied to find possible solutions.

The purpose of CACC is to enable the sharing of velocity data, allowing platooned vehicles to safely travel at higher speeds with smaller uniform headways than the $62 \mathrm{~m}$ figure advised by the Highways Agency. If the identified minimum safe platoon headway of $24.46 \mathrm{~m}$ were to be applied at speeds of 
$70 \mathrm{mph}$ then traffic flow could reach 9,213 vph, more than coping with the maximum volumes observed on the A14 during peak hours. Similar constant velocities and uniform headways could be maintained through high volume vehicle co-operation, generating steady state traffic flow and reducing stop and start conditions. The ability of all vehicles to adhere to close driving patterns would also dampen the amplification of speed variations as they propagate upstream. The effect of damping would reduce the frequency of instances where traffic stops for no apparent reason.

The Design Manual for Roads and Bridges (Department for Transport, 2006) acknowledges the principle that small vehicle headways can create traffic flow disturbances especially where traffic joins the highway from a slip road. The maintenance of a $24.46 \mathrm{~m}$ uniform platoon headway should provide sufficient room for the lateral interaction of vehicles that want to change lane and enter or leave the carriageway using slip roads. Bearing in mind that the A14 study area has 13 separate junctions, it is important to consider the lateral movement of vehicles in relation to platoon behaviour to ensure traffic flow is not disrupted.

\section{$\mathrm{CO}_{2}$ Emissions}

Due to the stop and start nature of driving on the A14 engine load is significantly increased when compared to free flowing traffic, resulting in higher fuel consumption for every mile covered. The subsequent GHG emission increases have resulted in two sections within the A14 case study being assigned Air Quality Management Area (AQMA) status because limits of the UK Environment Act (1995) have been breached (Department for Transport, 2011).

For an assessment of how $\mathrm{CO}_{2}$ emissions could be influenced by reducing congestion, the Comprehensive Modal Emissions Model (CMEM) sponsored by the U.S Environmental Protection Agency (Boriboonsomsin \& Barth, 2008, ) is used here to measure the difference between traffic that flows at steady state velocity and traffic that flows in stop and start conditions. The model takes into account the $\mathrm{CO}_{2}$ emission profiles of 30 separate vehicle categories ranging from small cars to HGVs. This identifies how $\mathrm{CO}_{2}$ emissions could be reduced if traffic flow is smoothed out on the A14 during peak hours. 


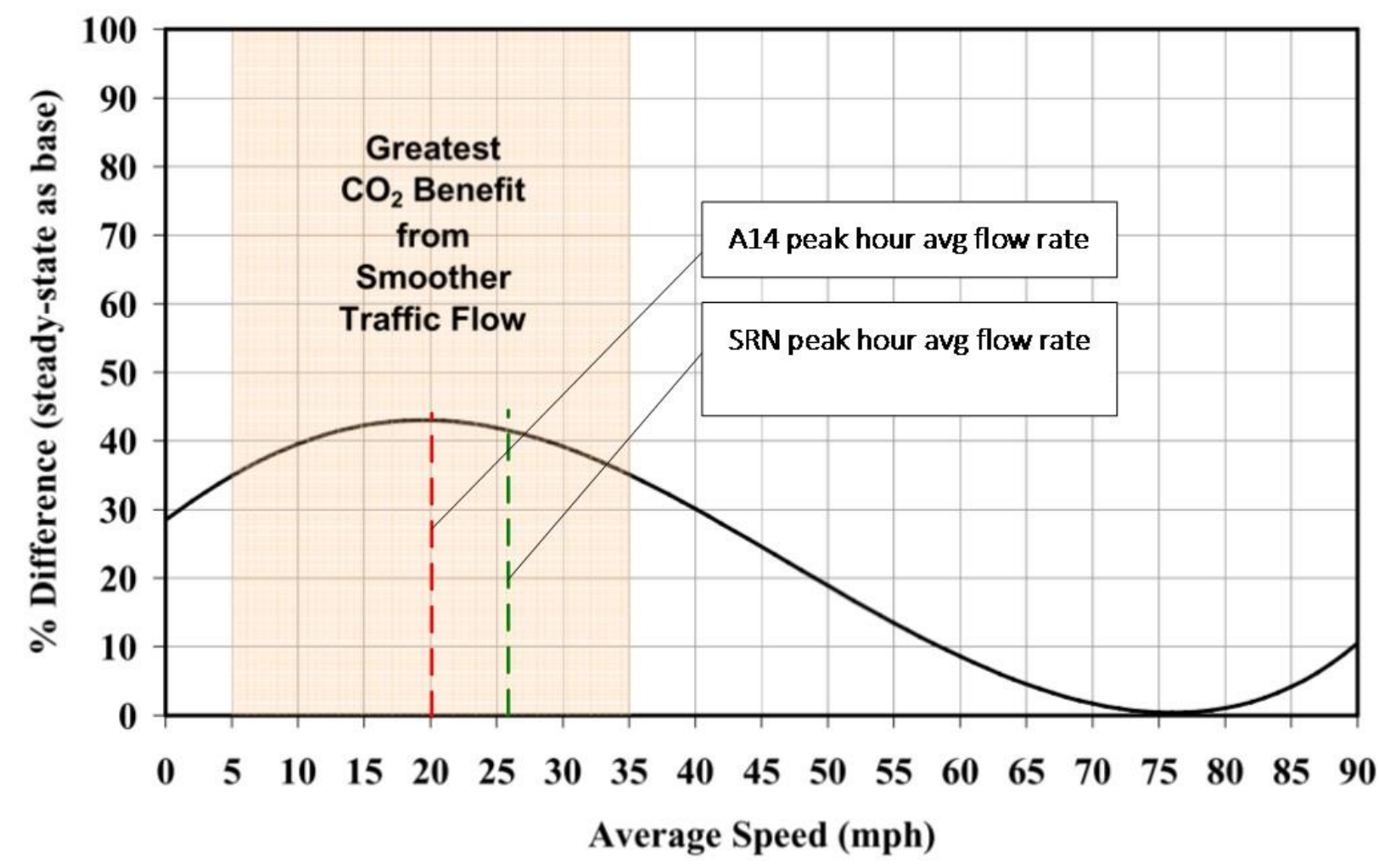

Figure 5: Potential $\mathrm{CO} 2$ emission reductions resulting from speed changes and smoother traffic flow; A14 and Strategic Road Network (SRN) average peak hour flow rates added to articulate potential emission savings (adapted from Boriboonsomsin \& Barth, 2008)

Traffic moving at an average speed of $20 \mathrm{mph}$ in stop and start conditions is shown to emit $43 \%$ more $\mathrm{CO}_{2}$ than traffic travelling at a $20 \mathrm{mph}$ average speed at steady state flow (Boriboonsomsin \& Barth, 2008). Average flow speed on the $\mathrm{A} 14$ is also $20 \mathrm{mph}$ during peak hours indicating that very high $\mathrm{CO}_{2}$ emission savings could be made by bringing traffic to steady state flow. Reducing emissions by $43 \%$ would positively contribute to any strategy aiming to rid the A14 of its AQMA status. From a holistic viewpoint if such savings were achieved on wider road networks they could significantly contribute to 2050 IPCC $\mathrm{CO}_{2}$ reduction targets .

\section{Accident rates}

Accident rates are unusually high in the A14 study area where road closures occur at a rate of approximately 200 per year, each lasting an average of 2.1 hours (Department for Transport, 2011).

A study of 700,000 accidents on UK roads carried out by the Institute of Advanced Motorists found that $87 \%$ of them were attributed to human error. The most common cause related to 'reaction factors' meaning that drivers were often not able to predict or interpret hazards in time to avoid collisions. The significance to highway collisions is that driver reaction is reported as a cause in a larger proportion of accidents on motorways than on minor roads. Impairment and distraction were also identified as the 
causes for a large proportion of motorway accidents (Institute of Advanced Motorists, 2009). Highway accidents tend to involve rear end collisions possibly explained by the fact that human motion perception is weaker in the field of depth (Green, 2013), meaning that vehicle closing distances are interpreted ineffectively.

CACC and CMB create an acute level of situational awareness that should reduce reaction factors leading to accidents. A platooned vehicle should know the driving pattern of the preceding vehicle quickly enough to allow automatic reaction to speed changes and where the need arises CMB can be applied to help avoid rear end collisions. Both autonomous systems should therefore reduce the potential for slow human driver reactions and limited motion perception to contribute towards accidents on highways. The identified minimum safe platoon headway of $24.46 \mathrm{~m}$ should ensure that platoon application risks do not add to the risk of rear end collisions.

The use of technology to assist human drivers in managing safety critical controls could lead to an increased perception that there is less need to pay attention to road conditions as collisions will be avoided automatically. This could inadvertently lead to increased risk of accidents as the driver becomes more distracted. In cars containing Level $2 \mathrm{AV}$ systems the driver is assumed to be in full control of the vehicle (NHTSA, 2013,) meaning it is essential that focus is maintained on highway conditions. Volvo are aware that such risks exist and are developing dashboard mounted driver monitoring (DM) sensors to detect driver distraction and impairment. The sensor is capable of constantly monitoring eye movements to detect whether vision leaves the road for a significant time period and alerting the driver to bring their attention back to the road if a distraction is detected (Volvo Ltd, 2014, online). If used alongside $C A C C$ and $C M B, D M$ systems should further reduce the number of accidents caused by distraction or impairment.

\section{Journey Time reliability}

Road users are generally unable to plan journeys efficiently on the A14 during peak hours because journey times are variable as a result of sporadic congestion levels and high accident rates. Problems are caused for commuters who cannot afford to regularly be late for work and businesses that may lose revenue as a result of traffic delays. In some cases allocating extra time for each journey may not be enough because A14 closures occur that last for hours on a regular basis. 
Journey time reliability is considered a key performance measure for highway reviews and is rated as more important than journey speed for road users because it allows them to make more effective use of their time (Cambridge Systematics Inc, 2005).

The application of CACC facilitates the movement of heavy traffic towards steady state flow and away from stop and start conditions. Increases in steady state flow will improve the reliability of journey times on the $\mathrm{A} 14$ because traffic flows more freely and is disrupted less by congestion which is difficult to plan for. The relationship between journey time reliability, congestion levels and accident rates is a fairly simple one; increases in either congestion or accident rates lead to reductions in journey time reliability. Because the combined use of $\mathrm{CACC}, \mathrm{CMB}$ and DM reduce congestion and accidents, the potential to improve journey time reliability is high.

\section{The effect of Heavy Good Vehicles (HGVs) on A14}

HGVs can disrupt highway traffic flow because they travel at a maximum speed of $60 \mathrm{mph}$ and often use both lanes of dual-carriageways in the UK resulting in cars being slowed down where they cannot pass on either lane. Heavy Goods Vehicles make up 19\% of traffic on the A14 because it is part of the TransEuropean Network (TEN) for freight carriers; most HGV journeys to and from Europe use this section of highway (Department for Transport, 2011). The effect of HGVs reduces overall traffic speed from 70mph which would lead to reductions in the identified maximum throughput of $9213 \mathrm{vph}$. The application of CACC should be effective in automatically managing speed variations between HGVs and cars and although it would be necessary for cars to slow down, steady state traffic flow would be maintained. If traffic were to slow to a uniform speed of $60 \mathrm{mph}$ on the $A 14$, headways between cars would also reduce. Using kinematic equations to recalculate a minimum safe platoon headway necessary at $60 \mathrm{mph}$ produces an interesting result:

$$
H_{s}=\frac{1}{2 \times 6.5 \mathrm{~m} / \mathrm{s}^{2}} \times 26.6^{2}-\frac{1}{2 \times 8.125 \mathrm{~m} / \mathrm{s}^{2}} \times 26.6^{2}+26.6 \mathrm{~m} / \mathrm{s} \times 0.3 \mathrm{~s} \quad=18.86 \mathrm{~m}
$$

Uniform headways of $18.86 \mathrm{~m}$ at $60 \mathrm{mph}$ increases maximum throughput to $10,231 \mathrm{vph}$, but the calculations are limited as they do not consider that HGVs decelerate more slowly than cars. If HGVs were to participate in platooning, as would be necessary on the A14 to realise the identified sustainability benefits, it is expected that increased headways (greater than 18.86) would be necessary to minimise the risk of rear end collisions where HGVs follow cars and so would reduce the maximum throughput . 
HGV deceleration rates vary significantly based on weight which can range from 15 tonnes un-laden to 40 tonnes at maximum payload (European Transport Safety Council, 2011, online). Additionally there are a number of further factors that increase deceleration variations including: load retention, vehicle suspension limitations, vehicle stability and braking system type (Department for Transport, 2004, online). Analysing these effects would allow the average deceleration performance of HGVs to enable the calculation of a minimum safe platoon headway to be computed as above ( but not attempted here).

\section{Challenges}

There are currently no signs that a standardised version of CACC has been developed to enable universal vehicle compatibility. Toyota has confirmed its intention to introduce an in-house version of CACC to the market by 2016 (Toyota-USA, 2013, online), indicating that a system is currently in development and is expected to be released within a few years. A standardised version is probably further on the horizon with the high level of research and development activity suggesting this could be available within 5 years.

Regulatory activity is moving towards mandating that manufacturers include certain Level $2 \mathrm{AV}$ systems in all new vehicles built. The American National Highway Traffic Safety Administration (NHTSA) has confirmed plans to introduce a regulatory proposal mandating that all new registered light utility vehicles contain V2V telematics after a certain date ( yet to be established) (NHTSA, 2014, online). NHTSA has also expressed its desire to stimulate the automotive market towards an accelerated development programme of $\mathrm{V} 2 \mathrm{~V}$ technology with the specific aim of achieving high market penetration; a condition needed for high volume vehicle platooning on highways.

Without regulatory intervention, factors exist that could limit the possibility of $\mathrm{V} 2 \mathrm{~V}$ technology becoming widely adopted on highways including economic cost and consumer choice. Some manufacturers could choose to exclude V2V communication systems from cheaper models in their product ranges to offer consumers the most competitive prices possible as a marketing strategy. Consumers may choose not to voluntarily pay for $\mathrm{AV}$ technology if they are unaware of the benefits that it could provide. In unregulated circumstances moderate volume deployment of CACC is the best scenario to be expected; a scenario that would limit the realisation of identified sustainability benefits.

In establishing an overall timeframe before high volume deployment of CACC could occur it is estimated that the necessary policy steps will not be taken for at least another 5 years. Given that consumers 
replace their cars every $10-15$ years on average (The Automotive Council UK, 2013) there appears to be an issue of technical lock-in that will only undo over time as old vehicles are replaced by new ones containing AV technology. Considering all challenges discussed, a likely timeframe before high volume deployment of CACC could occur is approximately 20 years (2035).

\section{Discussion}

\section{Uncongested roads}

The Department for Transport (DfT) estimates that approximately $24 \%$ of journeys were not on time on the English Strategic Road Network during 2012 (Symonds, 2013,) implying that many English roads do not have major congestion problems. Although systems like Co-operative Adaptive Cruise Control (CACC) would significantly enhance the driving experience by providing the driver and passengers a more relaxing and smoother driving conditions, there is no opportunity to reduce congestion where none exists. The holistic ability of $\mathrm{AV}$ technology to reduce congestion on road networks containing a mix of uncongested and congested highways would therefore be reduced. Potential emissions savings of $43 \%$ possible on a busy section of the A14 achieved through smoothing traffic flow speeds (would not be applicable to all highways, significantly reducing the overall potential to achieve emission reductions.

Collision Mitigation Braking (CMB) and Driver Monitoring (DM) appear to have a more diverse capability to reduce accident rates in a wide range of conditions. Distraction and impairment are human factors that lead to accidents and are still present on uncongested highways. Considering that uncongested highways naturally flow at a much quicker rate than congested highways there is potential for the severity of accidents to increase, even if their frequency is reduced. DM and CMB are not dependent on high volume deployment to be effective like CACC, so for every vehicle on the road that contains them a positive safety benefit can be achieved. Added to the potential for accidents on uncongested road to be more severe, the potential for $\mathrm{CMB}$ and $\mathrm{DM}$ to reduce accident rates remains high.

\section{Transport Policy}

Without policy intervention it is unlikely that the sustainability benefits from a move towards fully autonomous vehicles would be achievable because high volume deployment would not occur. Road transport policy is therefore a critical component in driving the improvement of highway sustainability, and delays in policy implementation would result in the identified sustainability benefits being delayed or failing to materialise. 
There is a good chance that $\mathrm{V} 2 \mathrm{~V}$ technology, the platform upon which CACC based, will be mandated for all highway vehicles in future but this is not guaranteed. The capabilities of automotive manufacturers and researchers to demonstrate the potential benefits of CACC to regulatory authorities will be a key influential factor in determining if and when mandatory policy is introduced. $\mathrm{V} 2 \mathrm{~V}$ communication has already been standardised under protocol $802.11 \mathrm{p}$ so that universal telematic compatibility will be guaranteed internationally. The next step is to achieve the same for CACC, allowing universal platooning capability. If CACC can be standardised under International Standards Organisation (ISO) regulations there is a greater chance of influencing transport policy on a global scale, creating a higher likelihood that all highly motorised nations will participate.

\section{External Influences}

Considering that traffic volumes on key strategic roads are already pushing capacity limits, it is difficult to understand how they will cope with predicted $50 \%$ volume increases by 2050 . Such peak hour increases may raise traffic levels to $10,500 \mathrm{vph}$, beyond where uniform platoon headways of $24.46 \mathrm{~m}$ can be maintained indicating that traffic flow would break down on highways even where CACC is in operation.

The forecast of a doubled global vehicle population indicates that road transport demand should be addressed to ensure that traffic volumes do not become unmanageable. Road transport policy can play a part in reducing road transport demand by developing viable alternatives to motorised transport and incentivising people to lower their use of private vehicles where possible. Increases in road building and vehicle manufacturing may also increase as a consequence of increased road transport demand as transport planners and manufacturers try to accommodate road user needs. $\mathrm{CO}_{2}$ emissions will be increased as a result and are beyond the potential influence of Autonomous Vehicle technology to fully mitigate.

Autonomous Vehicle technology is just one facet in a very complex transport system leading where the sustainability criteria will be influenced by external factors including road transport demand and road transport policy. The combination of influential factors discussed, including Autonomous Vehicle technology, provides an opportunity for the intelligent use of transport policy to target the optimised use of existing highways without exceeding capacity limits. If planners recognise that road transport demand could lead to traffic volumes exceeding 10,000vph on some highways then transport policies could be developed aiming to reduce demand to manageable levels. The benefits of a multi-faceted approach to managing the holistic transport system could lead to reductions in road construction and vehicle manufacturing levels where road transport demand is reduced. $\mathrm{CO}_{2}$ emissions would then be 
reduced in three dimensions: transport operations, vehicle manufacturing and road construction. If road transport demand levels are kept to within limits that allow CACC to operate effectively, reduced $\mathrm{CO}_{2}$ emissions will be complemented by reduced congestion, reduced accident rates and improved journey time reliability.

\section{Sustainability assessment}

Now that a clearer understanding of where $\mathrm{AV}$ technology sits within the holistic transport system has been established, it is possible to consolidate a sustainability assessment of Level 2 Autonomous Vehicle technology identifying where it can have the greatest influence and areas where its potential is more limited. This is summarised in Table 2.

\section{CONCLUSION}

Sustainability of road transport can be improved through the introduction of autonomous vehicle (AV) technology by exploring its potential to optimise the flow of traffic on highways. There are limitations in the capabilities of human drivers that deny the opportunity for high volume vehicle co-operation on highways and while these limitations remain, traffic will never flow in an optimised way. There are Level $2 \mathrm{AV}$ systems available that can address these limitations and potentially optimise traffic flow by making the most of existing highway space.

Organisations testing highway platooning seem to be optimistic about the safe maintenance of small platoon headways at highway speeds. However there is little evidence to suggest that the identified application risks have been evaluated with enough scientific veracity to justify this optimism. Safe headway distances are significantly greater than the $10 \mathrm{~m}$ platoon headway currently being tested. The calculations used to determine this are primarily based on mechanical braking variations that are very unlikely to change in the foreseeable future, so it is difficult to see how small uniform headways can be applied safely using current technology.

However a safe minimum platoon headway of $24 \mathrm{~m}$ at $70 \mathrm{mph}$ can still significantly improve the sustainability of traffic on existing highways. It is known by highway authorities that traffic flow is disrupted where small headways exist between vehicles because insufficient space exists for lateral interaction. Considering that lateral interaction is a common occurrence on highways, the case for 


\begin{tabular}{|c|c|c|c|}
\hline Criteria & Condition & Description & $\begin{array}{l}\text { Potential to improve } \\
\text { sustainability }\end{array}$ \\
\hline \multirow[t]{3}{*}{$\begin{array}{l}\mathrm{CO}_{2} \\
\text { Emissions }\end{array}$} & Congested Roads & $\begin{array}{l}\text { - Effective use of CACC (assisted by CMB) can potentially lead to } 43 \% \text { emission reductions. CACC enables co-operative } \\
\text { driving and accurate vehicle platooning in a way that is beyond the control of human drivers. } \\
\text { - The ability of CACC to reduce emissions is limited by a theoretical maximum throughput of } 9213 \text { vph on dual } \\
\text { carriageways and is vulnerable where road transport demand becomes too high, leading to potential for traffic flow to } \\
\text { breakdown and increase emissions even where CACC is in operation. } \\
\text { - AV technology cannot influence } \mathrm{CO}_{2} \text { emissions generated by manufacturing and road construction brought about by } \\
\text { increased road transport demand }\end{array}$ & $\begin{array}{l}\text { High } \\
\checkmark \checkmark \checkmark\end{array}$ \\
\hline & $\begin{array}{l}\text { Mixed Roads } \\
\text { (Congested } \\
\text { and Uncongested) }\end{array}$ & $\begin{array}{l}\text { - Emission reductions are lower where congestion is low as traffic tends to flow well. The ability of CACC to reduce } \\
\text { congestion on a mix of roads is reduced. } \\
\text { - } \mathrm{CO}_{2} \text { emissions can be reduced by systems like CMB and DM as their ability to lower accident rate will also reduce traffic } \\
\text { jams caused by road closures. }\end{array}$ & $\begin{array}{l}\text { Moderate } \\
\text { to Low } \\
\checkmark \checkmark\end{array}$ \\
\hline & $\begin{array}{l}\text { Emissions } \\
\text { (2050 IPPC) }\end{array}$ & $\begin{array}{l}\text { - Based on estimates that the requisite market penetration may occur in approximately } 20 \text { years, CACC could be in full } \\
\text { operation on highways by } 2035 \text { in time to meet IPCC CO2 emission reduction targets for } 2050 \text {. } \\
\text { - Large forecasted growth in road transport demand could compromise identified carbon emission reductions unless } \\
\text { transport policy is implemented effectively to limit highway traffic volumes. }\end{array}$ & Moderate \\
\hline \multirow[t]{2}{*}{ Congestion } & $\begin{array}{l}\text { On congested } \\
\text { highways }\end{array}$ & $\begin{array}{l}\text { - CACC enables uniform headways and similar constant velocities to be maintained between groups of vehicles (platoons), } \\
\text { identified as key parameters to enable congestion reduction. Traffic is managed to create steady state flow even where } \\
\text { volume is high, improving congestion significantly } \\
\text { - The influence of road transport demand may mean that future traffic throughputs are beyond the control of CACC } \\
\text { meaning that congestion could occur even in the presence of the technology }\end{array}$ & $\begin{array}{l}\text { High } \\
\sqrt{ } \sqrt{ }\end{array}$ \\
\hline & $\begin{array}{l}\text { Mixed Roads } \\
\text { (Congested } \\
\text { and Uncongested) }\end{array}$ & $\begin{array}{l}\text { - CACC can only influence congestion where it is a significant issue. As many highways on the Strategic Road Network are } \\
\text { uncongested the overall potential to reduce congestion is significantly reduced }\end{array}$ & $\begin{array}{l}\text { Low } \\
\checkmark\end{array}$ \\
\hline $\begin{array}{l}\text { Accident } \\
\text { rate }\end{array}$ & & $\begin{array}{l}\text { - Accident rate appears to be the biggest benefit of AV technology. CMB and DM are versatile and can operate effectively } \\
\text { in all road conditions without the need for high volume deployment. The systems control the human factors that lead to } \\
\text { accidents very effectively. } \\
\text { - CACC also reduces accident rates by establishing safe platoon headways. Reducing congestion directly reduces accident } \\
\text { rate } \\
\text { - As increased flow leads to higher speeds, potentially increasing accident severity, CMB and DM address the human } \\
\text { factors that lead to accidents meaning the risk of severe accidents is also reduced. }\end{array}$ & $\begin{array}{l}\text { High } \\
\checkmark \checkmark \checkmark\end{array}$ \\
\hline Journey time & & $\begin{array}{l}\text { - Journey time reliability is closely coupled with congestion. Where congestion increases, journey time reliability } \\
\text { decreases. A combination of CACC, CMB and DM contribute to reduce congestion and accident rates meaning journey } \\
\text { times will improve in speed and reliability }\end{array}$ & $\begin{array}{l}\text { High } \\
\checkmark \checkmark \checkmark\end{array}$ \\
\hline
\end{tabular}

Table 2: Sustainability assessment matrix 
longer platoon headways that can still lead to improvements in highway sustainability appears to be strengthened.

Transport policy plays a vital part in driving the tasks necessary to enable high volume deployment of Co-operative Adaptive Cruise Control (CACC). If appropriate policies are implemented by all highly motorised nations within the next five years the anticipated benefits to congestion, accident rates, $\mathrm{CO}_{2}$ emissions and journey time reliability could materialise by 2035. From a timeframe perspective it means that the Level $2 \mathrm{AV}$ systems investigated should contribute to IPCC CO2 emission reduction targets for 2050. Nonetheless, achieving the range of policy implementations necessary is a major task and could be the dimension most likely to hinder the development CACC.

Issues which need addressing are as follows. Vehicle category based minimum safe platoon headways should be assimilated into transport policy to establish safety standards. The NHTSA has set a precedent in mandating $\mathrm{V} 2 \mathrm{~V}$ technology in all small cars sold in America. The policy should be expanded to cover all vehicle categories and also be adopted by other countries with high motorisation rates. Manufacturers should develop CACC collaboratively to ensure universal compatibility and lead development towards the system being standardised by the International Standards Organisation. Because V2V communication has already been standardised under protocol $802.11 \mathrm{p}$, standardising CACC is a logical further step in development. CACC development should then follow the same policy pathway as $\mathrm{V} 2 \mathrm{~V}$ technology to ensure that high volume deployment remains feasible within a 20 year timeframe. Because CACC is reliant on CMB to operate effectively where small platoon headways are maintained, any policies that standardise or mandate CACC inclusion in new vehicles should include $\mathrm{CMB}$. 


\section{References}

Bergenhem, C. et al (2012). Vehicle-to-Vehicle Communication for a Platooning System, (Transport Research Arena 2012, Volume 48, Pages 1222 - 1233, DOI: 10.1016/j.sbspro.2012.06.1098)

Boriboonsomsin, K. \& Barth, M. (2008). Real-World CO 2 Impacts of Traffic Congestion, (Transportation Research Record: Journal of the Transportation Research Board, DOI: 10.3141/2058-20)

Cambridge Systematics Inc. (2005). Traffic Congestion and Reliability; Trends and Advanced Strategies for Congestion Mitigation. (Texas Transportation Institute, URL:

http://ops.fhwa.dot.gov/congestion report/congestion report 05.pdf)

Davis, S. C. et al (2011). Transport Energy Data Book: Edition 30, (Centre for Transportation Analysis, USA: http://info.ornl.gov/sites/publications/files/Pub31202.pdf)

Delphi Corporation. (2009). Delphi Collision Mitigation System, (Delphi Corporation, USA, URL: http://delphi.com/shared/pdf/ppd/safesec/cms.pdf)

Department for Transport. (2004). Project: Limiting Factors For Improving Heavy Goods Vehicle Brake Performance, (TRL Ltd, UK, URL: http://www.dft.gov.uk/rmd/project.asp?intProjectID=7944)

Department for Transport. (2006). Design Manual for Roads and Bridges. Volume 6, Section 2, Part 1, (Highways Agency, UK, URL: http://www.dft.gov.uk/ha/standards/dmrb/vol6/section2/td2206.pdf)

Department for Transport. (2011). A14 Study Output 1, (Steer Davies Gleave, London, URL: https://www.gov.uk/government/uploads/system/uploads/attachment data/file/2649/a14-study.pdf)

Douglass, B. L. Jr. (2002). Induced Demand and Elasticity, (U.S. Department of Transportation, URL: http://isddc.dot.gov/OLPFiles/FHWA/010619.pdf)

Driver and Vehicles Standards Agency (UK). (2007). The Highway Code: General rules, techniques and advice for all drivers and riders (103 to 158). Typical Stopping Distances. (Highways Agency, UK, URL: https://www.gov.uk/general-rules-all-drivers-riders-103-to-158/control-of-the-vehicle-117-to-126)

Edenhofer, O. et al (2014). Summary for Policymakers: Contribution of Working Group III to the Fifth Assessment of the Intergovernmental Panel on Climate Change, (Cambridge University Press, UK, URL: http://report.mitigation2014.org/spm/ipcc_wg3_ar5_summary-for-policymakers_approved.pdf)

European Transport Safety Council. (2011). ETSC position on Longer and Heavier Goods Vehicles on the roads of the European Union, (ETSC, Brussels, URL: http://archive.etsc.eu/documents/ETSC_Position_on_Longer_and_Heavier_Vehicles.pdf)

Fernandes, P. \& Nunes, U. (2012). Platooning With DSRC-Based IVC-Enabled Autonomous Vehicles: Adding Infrared Communications for IVC Reliability Improvement. (Intelligent Vehicle Symposium, Spain, Jun 3 - 7, 2012, DOI: 10.1109/IVS.2012.6232206)

Green, M. (2013). The Psychology of Rear End Collisions: Looming. (Visualexpert.com, UK, URL: http://www.visualexpert.com/Resources/rearendcollision.html) 
Huang, M. (2002). Vehicle Crash Mechanics. (London: CRC Press, URL: http://roadsafellc.com/NCHRP2224/Literature/Papers/Vehicle Crash Mechanics.pdf)

Institute of Advanced Motorists. (2009). Licensed to skill: contributory factors in road accidents. (IAM, London, URL: http://www.iam.org.uk/images/stories/policy-research/licensetoskill.PDF)

International Energy Agency (2012). CO2 Emissions from Fuel Combustion: Highlights, (IEA, Luxembourg, URL:

http://www.iea.org/publications/freepublications/publication/CO2emissionfromfuelcombustionHIGHLI

GHTSMarch2013.pdf)

International Transport Forum (2011). Transport Outlook: Meeting the Needs of 9 Billion People. (ITF, Paris, URL: http://www.internationaltransportforum.org/Pub/pdf/110utlook.pdf)

Juliussen, E. \& Carlson, J. (2014). Emerging Technologies: Autonomous Cars- Not if, but when, (IHS Automotive, Colorado, URL:

http://orfe.princeton.edu/ alaink/SmartDrivingCars/PDFs/IHS\%20 EmergingTechnologies Autonomous Cars.pdf)

MIRA. (2014). Average Braking Distance vs Tread Pattern Depth Wet Asphalt. (Motor Industry Research Association, UK, URL: http://www.3mmtyres.co.uk/)

NHTSA. (2013). National Highway Traffic Safety Administration Preliminary Statement of Policy Concerning Automated Vehicles. (NHTSA, Washington DC, URL:

http://www.nhtsa.gov/staticfiles/rulemaking/pdf/Automated Vehicles Policy.pdf)

NHTSA. (2014). U. S Department of Transportation Announces Decision to Move Forward with Vehicleto-Vehicle Communication Technology for Light Vehicles. (NHTSA, Washington DC, URL:

http://www.nhtsa.gov/About+NHTSA/Press+Releases/2014/USDOT+to+Move+Forward+with+Vehicleto-Vehicle+Communication+Technology+for+Light+Vehicles)

Petrie, G. "Current Developments in Airborne Laser Scanners Suitable for Use on Lightweight UAVs." GEO Informatics 8 Dec. 2013. (URL: http://fluidbook.geoinformatics.com/GEOInformatics 8 2013/index.html\#/1/)

Ploeg, J. et al (2011). Design and Experimental Evaluation of Cooperative Adaptive Cruise Control. (14th International IEEE Conference on Intelligent Transportation Systems, pp. 260-265, DOI:

10.1109/ITSC.2011.6082981)

Ploeg, J. (2012). Cooperative Adaptive Cruise Control: A Real-Time Cooperative Driving System, (TNO Technical Services, URL:

http://www.rin.org.uk/Uploadedpdfs/ItemAttachments/7\%20Ploeg 2012 Cooperative Adaptive Cruis e Control A Real-time Cooperative Driving System\%20-\%20RIN SDV\%20-

\%20Uni Notts March 2012-web.pdf)

Smith, A. (2012). SARTRE - Frequently Asked Questions (FAQ), (SP Technical Research Institute of Sweden, URL: http://www.sartre-project.eu/en/faq/Documents/SARTRE FAQ.pdf)

Symonds, J. (2013). Reliability of journeys on Highways Agency 's motorway and " $A$ " road network, (Department for Transport, UK, URL: 
https://www.gov.uk/government/uploads/system/uploads/attachment_data/file/49012/jan-2013congestion-ha-network-stats-release.pdf)

Miles, J. et al (2013). Intelligent Mobility Technology Roadmap, (The Automotive Council UK)

The Shift Project Data Portal (2014). Breakdown of GHG emissions by Sector and Gas, (The Shift Project, Paris, URL: http://www.tsp-data-portal.org/Breakdown-of-GHG-Emissions-by-Sector-and-Gas)

Toyota (USA). (2013). Toyota to Launch Advanced Driving Support System Using Automated Driving Technologies in Mid-2010s, (Toyota Motor Sales, USA, URL:

http://corporatenews.pressroom.toyota.com/releases/toyota+advanced+driving+support+system+tech nology.htm)

Volvo Ltd. (2014). Volvo Cars conducts research into driver sensors in order to create cars that get to know their drivers. (Volvo, Sweden, URL: http://www.volvocars.com/uk/top/about/newsevents/pages/default.aspx?itemid=219)

World Health Organisation (2013). Global Status Report On Road Safety 2013, (WHO, Switzerland, URL: http://www.who.int/violence injury prevention/road safety status/2013/en/)

Zahren, M (2012). The Global Vehicle Population - Aftermarket potential for remanufactured parts, (Polk \& Co, URL: http://www.mera.org/Document-Vault/Presentations/2013/Polk-PresentationReMaTec2013-FINAL.pdf)

Zhou, H. et al (2012). Vehicle Platoon Control in High-Latency Wireless Communications Environment. (Transportation Research Record: Journal of the Transportation Research Board, Volume 2324, Pages 81 - 90, DOI:10.3141/2324-10) 


\section{List of Figure Captions}

Figure 1: Different Levels of Autonomous Vehicle Technology (Developed from: NHTSA, 2013)

Figure 2: V2V telematics enable vehicle platooning using CACC.

Figure 3 : Car following pattern for platoon of 6 cars (adapted from (Ploeg, 2012))

Figure 4: Contextualising Equation 2 parameters

Figure 5: Potential $\mathrm{CO} 2$ emission reductions resulting from speed changes and smoother traffic flow; A14 and Strategic Road Network (SRN) average peak hour flow rates added to articulate potential emission savings (adapted from Boriboonsomsin \& Barth, 2008)

\section{List of Table captions}

Table 1: Calculation of minimum safe platoon headway in four scenarios

Table 2: Sustainability Assessment Matrix

\section{Glossary of Terms}

CACC Co-operative Adaptive Cruise Control

CMB Collision Mitigation Braking

AV Autonomous Vehicles

V2V Vehicle to Vehicle

\section{Mathematical terms}

$\mathrm{N}_{\mathrm{veh}}=$ number of vehicles per hour per lane

$\mathrm{T}_{\min }=$ minimum safe headway in seconds (distance/speed)

$H_{s}=$ safe headway $(m)$

$a=$ deceleration $\left(\mathrm{m} / \mathrm{s}^{2}\right)$

$\mathrm{v}=$ velocity $(\mathrm{m} / \mathrm{s})$;

$T_{r}=$ Reaction time of platoon 